\title{
Fabrication Assessment Method for Dimensional Quality Management of Curved Plates in Shipbuilding and Offshore Structures
}

\author{
Ki-Youn Kwon ${ }^{*}$ and Jaeyong Lee $\oplus^{\text {*x }}$ \\ "School of Industrial Engineering, Kumoh National Institute of Technology, Gumi, Korea \\ "Department of Naval Architecture and Ocean Engineering, Dong-eui University, Busan, Korea

\section{선박 및 해양 구조물 곡부재 치수 품질 관리를 위한 가공완성도 평가} \\ 권기연 ${ }^{*}$ 이재용*ㅊ \\ *금오공과대학교 산업공학부 \\ *동의대학교 조선해양공학과
}

KEY WORDS: Assessment of completion 완성도 평가, Curved plate 곡부재, Dimensional quality management 치수 품질 관리, Surface registration 곡면 정합

\begin{abstract}
The forward and afterward parts of ships and offshore structures are designed to improve the fuel consumption performance. These are made of curved plates with a large thickness. If a fabricated curved plate has some dimensional errors, a lot of additional cost is incurred in the assembly process. Thus, an accurate dimensional assessment is very important for fabrication. In this paper, we propose an assessment method for the dimensional quality management of curved plates. This can be applied to data measured using a variety of three-dimensional instruments, with boundary measurement points automatically classified and sorted to create a measurement surface. The assessment is evaluated after matching the $C A D$ surface and the measured surface considering constrained conditions. The fabrication assessment is evaluated as a probability of how much the tolerance is satisfied.
\end{abstract}

\section{1. 서 론}

선박 및 해양 플랜트 일부 선종의 선수미 부분은 추진 저항을 감소시켜 연비를 증가시키기 위해 Fig. 1과 같이 다양한 곡률을 가지는 곡면으로 이루어져 있다. 일반적으로 $20 \sim 50 \mathrm{~mm}$ 내외의 두꺼운 철판으로 구성되어 있으며 1 2m 크기의 곡부재를 만들 어 용접을 통해 블록을 조립한다. 선수미 곡부재 가공에 대한 자동화는 많은 연구가 이루어졌지만(Bae et al., 2012; Park et al., 2016; Zhang et al., 2011; Zhou et al., 2014), 기존 작업을 모두 대체할 만큼 아직 상용화가 되지는 않고 있다. 일부 단일 방향 곡률을 가지는 형상에 대해서는 냉간가공을 하고 있으나(Fig. 2(a)), 이를 제외한 것은 대부분 조선소들이 열간가공 방식을 이 용해서 곡부재를 가공하고 있다. 열간가공은 프레스(Press)를 이 용해서 한 쪽 방향으로 곡률 형상을 만든 후, 작업자들이 경험 에 의존하여 가스 토치를 이용해서 가열하고 물을 뿌려서 냉각 작업을 반복해서 설계 형상의 모양대로 만들어 가는 방식이다
(Fig. 2(b)). 가공의 완성도 평가를 위해 주로 나무 목형을 이용 하고 있으며(Fig. 2(c)), 최종 가공 후 치수 품질 체크를 위해 3 차원 계측기가 일부 활용되고 있다. 곡부재는 열간가공에 의해 만들어지므로 초기 치수 대비 수축 현상이 발생한다. 따라서 최 종 가공 후의 형상에 대한 정확한 예측이 어려워서 약간의 여 유 마진을 가지고 제작하며, 가열이 끝난 후에는 Fig. 2(d)와 같 이 마진을 절단해 준다.

가공된 곡부재의 완성도는 기본적으로 나무 목형 및 줄자를 이용해서 평가하여왔다. 곡률 평가는 목형을(Fig. 2(c)), 길이 및 거리는 줄자를 이용하는데, 나무 목형을 이용하는 경우에는 작 업자의 판단력에 의존하고 있다. 이로 인해 나무를 놓는 기준 위치와 방향에 따라 달라질 수 있으며, 일부 구간의 오차로 인 해 왜곡된 판단을 할 수가 있다. 특히 Fig. 2(c)와 같은 경우 나 무 목형의 기울어짐에 따라 다른 결과를 초래할 수 있다. 또한 줄자를 이용할 경우 측정 오차가 발생할 수 있으며, 열간가공으 로 인해 부재 끝 단이 매끄럽지 않은 경우가 많아서 계측 오차

Received 22 January 2018, revised 24 February 2018, accepted 12 April 2018

Corresponding author Jaeyong Lee: +82-51-890-2596, jlee@deu.ac.kr ORCID: http://orcid.org/0000-0002-4469-7765

\footnotetext{
(C) 2018, The Korean Society of Ocean Engineers

This is an open access article distributed under the terms of the creative commons attribution non-commercial license (http://creativecommons.org/licenses/by-nc/3.0) which permits unrestricted non-commercial use, distribution, and reproduction in any medium, provided the original work is properly cited.
} 


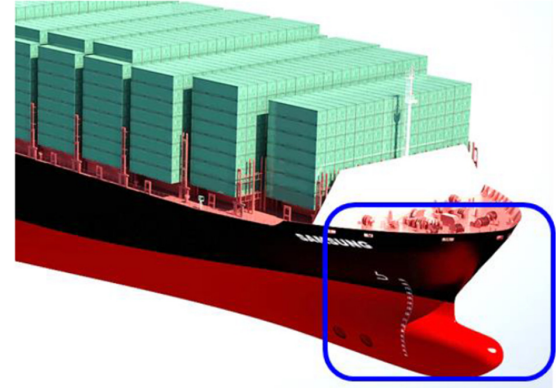

(a) Container

Fig. 1 Forward parts of ships and offshore structures

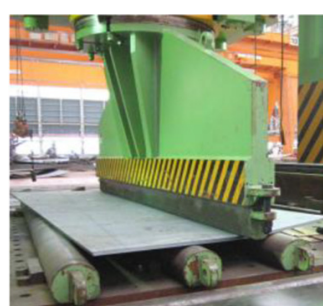

(a) Press roll bending

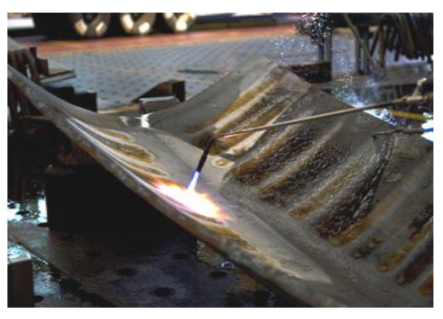

(b) Heating process
Fig. 2 Fabrication of a curved plate

를 유발 할 수 있다. 이와 같은 문제점 들을 보완하기 위해 3 차 원 계측시스템들이 활용되고 있다. 계측기를 이용해서 가공된 부재의 일부 포인트 또는 전체를 측정해서 계측곡면을 생성한 다. 일반적으로 선박 건조 과정에 있어서 블록의 치수 품질을 관리할 때는 주요 부재와 보강재가 교차하는 위치를 측정해서 포인트 기반으로 오차 분석을 수행한다(Kwan et al., 2015; Kwon, 2016). 그러나 곡부재의 경우는 내부 곡률에 따라서 오차 가 발생할 수 있으므로, 부재 곡면 전체가 관심대상이다. 상대 적으로 계측포인트가 많아서 최근에 3차원 레이저 스캐너(3D laser scanner)(Hiekata et al., 2011; Li et al., 2016) 및 사진계측시 스템(Photogrammetry)(Wang et al., 2016)이 주로 활용되고 있다. 측정된 데이터는 곡면으로 모델링하여 설계곡면과 비교하여 가 공완성도를 평가한다(Huang et al., 2015; Mehrad et al., 2014; Park et al., 2007). 곡부재는 가공 완성 후, 일부 면을 절단해야

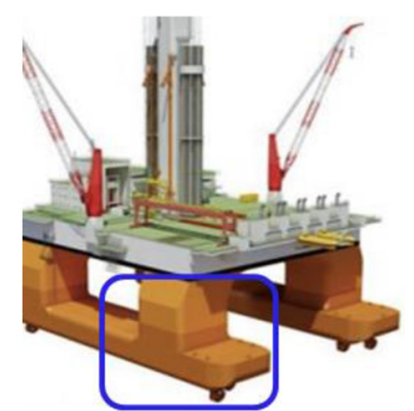

(b) Semi Submersible Rig

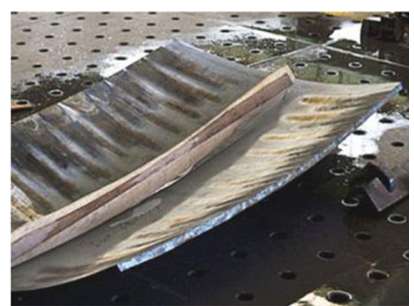

(c) Assessment of completion using a template

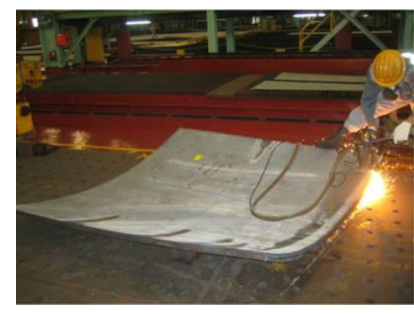

(d) Margin cutting

하는데, 절단 길이를 최소화 하기 위해 제한 조건을 고려한 곡 부재 정합 방법이 사용되었다(Park et al., 2007). 그리고 Park 등 (Park et al., 2016)은 레이저비전시스템(LVS, Laser vision system) 을 이용하여 자동으로 곡부재를 계측한 후 설계곡면과 비교하 여 가공완성도를 평가하였다. 기존 연구 사례들은 주로 계측곡 면과 설계곡면을 비교했을 때 거리 오차 값을 가공 완성도 수 치로 사용하였으며(Jung et al., 2009; Hiekata et al., 2011), 허용 공차를 고려해서 작업자가 직관적으로 판단할 수 있도록 $100 \%$ 에 가까운 것이 완성도가 높게 나오도록 수치적으로 표현했다 (Park et al., 2016).

현재 곡부재 치수품질 관리를 위해 사진계측시스템 및 3차원 레이저스캐너가 많이 활용되고 있다. 그러나 기존 연구 사례들 은 이와 같은 계측시스템으로 획득된 데이터에 대한 곡면 모델 링 및 분석에 대한 자동화 방법이 제시되지 않았다. Fig. 3은 본

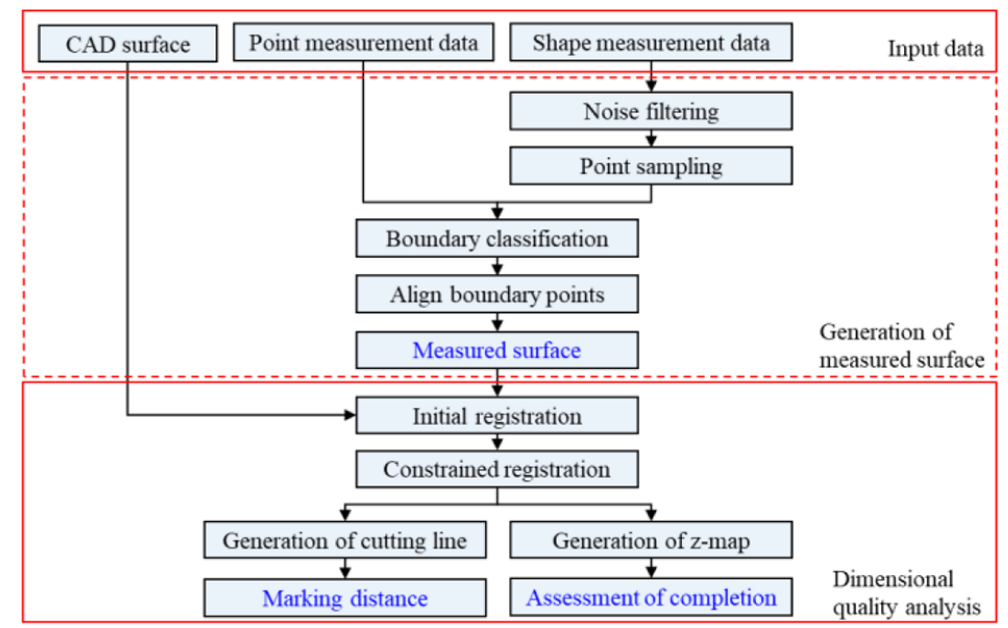

Fig. 3 Schematic of dimensional quality management process 
논문에서 제시하는 곡부재 치수품질 관리를 위한 전체 과정을 보여주고 있으며, 다양한 계측기로부터 획득된 데이터에 대해 가공 완성도를 평가할 수 있는 방법을 제안한다. 또한 별도의 마킹(Marking) 장비 없이 기존 계측데이터를 활용하여 여유 마 진을 절단할 수 있는 방법을 제안하고, 가공 완성도 평가에서 선박 건조의 특성을 고려하여 확률 개념을 추가로 도입하였다. 이는 작업의 효율성을 위해 모든 과정이 자동으로 이루어질 수 있도록 하였다. 측정된 데이터로부터 계측곡면을 자동으로 모 델링(Modeling)하고, 설계곡면과 제약조건을 고려하여 정합을 수행한 후, 가공완성도 및 최종 여유 마진 절단선을 산출한다. 특히 제약조건을 고려한 정합은 절단 길이를 최소화하기 위해 다양한 조건이 고려될 수 있도록 하였다. 본 논문의 구성은 다 음과 같다. 2절에서는 곡부재 계측에 사용되는 계측기에 대해서 소개하고, 3절에서는 자동 곡면 모델링에 대해 설명한다. 4절에 서는 제약조건을 고려한 곡면 정합 방법 및 가공완성도 계산 방법에 대해 설명하고, 5절에서 실험 및 검증 결과를 살펴보고, 6절에서 결론에 대해서 논의한다.

\section{2. 부재 계측}

곡부재의 경우는 내부 곡률에 따라서 오차가 발생할 수 있으 므로, 부재 곡면 전체가 관심 대상이다. 따라서 곡면을 측정한 포인트를 이용해서 생성된 계측곡면(Measured surface)과 설계곡 면(CAD surface)을 비교해서 가공 완성도를 평가한다. 현재 곡 부재를 측정하기 위해 이용되는 계측기는 일부 대표되는 점들 을 측정하는 방식과 곡면 전체를 계측하는 방식 두 가지로 구 분할 수 있다.

대표 포인트 측정 방식은 일부 포인트를 측정해서 곡면을 생

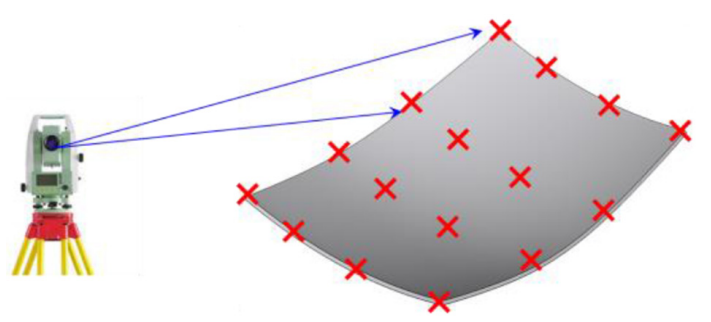

(a) Total station

Fig. 4 Points measuring method

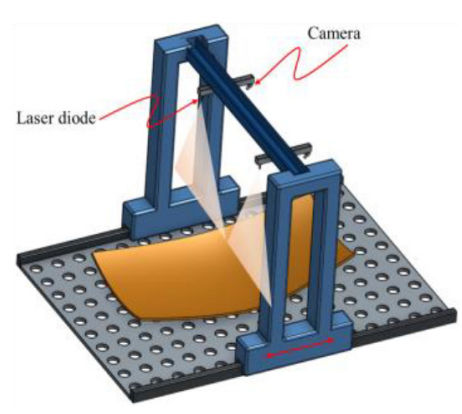

(a) Laser vision system
성하는 방식으로 측정 포인트의 개수 및 위치에 따라 실제 곡 면과 모델링된 곡면 사이에 많은 오차를 유발할 수 있다. 모델 링 오차를 최소로 가져가기 위해서는 곡률이 큰 곳에서는 좀 더 많은 포인트를 측정하고, 그렇지 않은 곳에서는 적은 포인트 를 균등하게 측정할 필요가 있다. 측정된 포인트를 이용해서 곡 면을 복원하는데, 많이 측정하면 할수록 복원된 곡면의 정밀도 가 향상될 수 있다. 그러나 측정 포인트가 증가함으로써 계측 시간이 많이 소요되므로 적절한 포인트 수가 필요하다. 일반적 으로 선수미 곡부재는 1 2m 정도의 크기이며, 곡률에 대한 관 리 수준은 $\pm 5 \mathrm{~mm}$ 정도이다. 따라서 곡면 복원 오차는 $1 \sim 2 \mathrm{~mm}$ 이 내로 가져가야 하며, 부재 곡률에 따라 차이가 있지만 대략적으 로 $20 \sim 100$ 개 정도의 포인트가 필요하다. 측정포인트 개수는 크 기 뿐만 아니라 모양에 따라 달라질 수 있으므로 향후 형상에 따라 적절한 포인트 측정 위치를 가이드 해주는 것이 필요하다. Fig. 4(a)는 토탈스테이션(Total station)을 이용하여 계측하는 방 식으로 비교적 정밀한 계측데이터를 획득할 수 있지만, 많은 측 정 시간이 소요되어 거의 사용되고 있지 않다. Fig. 4(b)는 사진 계측을 이용한 방법으로 정밀한 계측을 위해 타겟(Target)을 이 용하는 것이 필요하지만 빠른 시간 안에 측정이 가능하다. 사진 계측 시스템은 카메라, 타겟, 이미지로부터 3차원 좌표 값을 획 득하는 복원 SW 및 크기를 보정하는 스케일 바(Scale bar)로 구 성된다(Geodetic Systems, 2017).

전체 계측 방식은 곡부재의 모든 영역에 대해서 매우 조밀하 게 측정하는 방식이다. Fig. 5(a)는 갠트리(Gantry)에 장착된 LVS 를 이용하여 측정하는 방식이며, Fig. 5(b)는 3차원 레이저 스캐 너를 이용하여 측정하는 방식이다. 이는 타겟 없이 레이저를 이 용해서 곡면을 스캔(Scan)하는 방식이어서 빠른 시간 안에 많은 영역을 측정할 수 있지만, 계측 정밀도는 다소 떨어진다. 실 곡

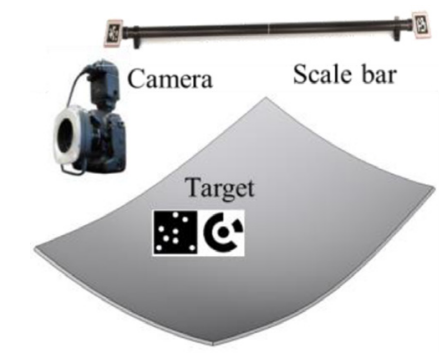

(b) Photogrammetry

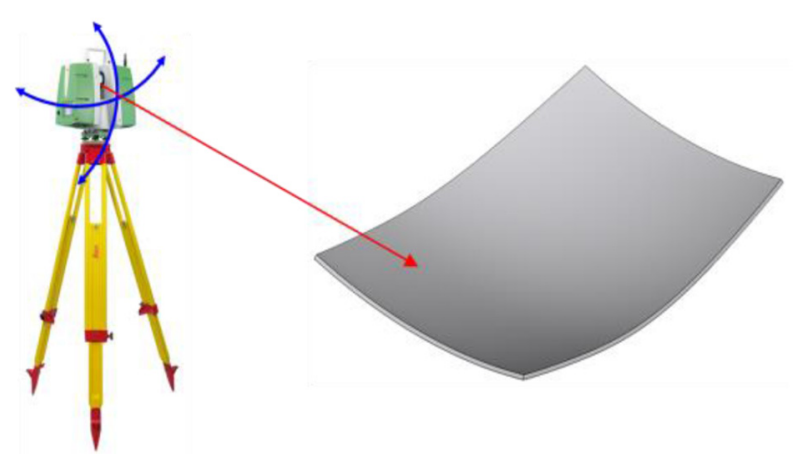

(b) 3D laser scanner

Fig. 5 Shape scanning method 
(a) Measured points using a total station(20 points)

Fig. 6 Examples of measured points (plate size: $1100 \times 800 \times 20$ )

부재의 경계에는 가열 작업으로 인해 검게 탄 부분 및 절단 작 업에서 발생하는 반짝이는 부분에 많은 노이즈가 존재하는데, 이로 인해 측정 오차가 많이 발생할 수 있다. 또한 부재는 두꺼운 판으로 구성되어 있어 정확한 부재 경계를 구분하기가 어렵다.

Fig. 6은 토탈스테이션 및 3차원 레이저 스캐너를 이용해서 곡 부재를 계측한 예를 보여준다. 해당 부재 크기는 길이 $1100 \mathrm{~mm}$, 폭 $800 \mathrm{~mm}$ 이며 포인트 계측의 경우 20 포인트를 측정하였다. 토 탈스테이션 경우에는 측정을 위해 타겟을 곡부재에 부착해야 하 는데, 설치 오차 및 측정을 위한 시준 오차가 발생할 수 있으며, $3 \mathrm{D}$ 레이저로 스캐닝 한 데이터는 부재 경계에서 많은 노이즈를 가지고 있다. 따라서 이와 같은 경우는 실제 제작된 곡부재의 에 지(Edge) 길이 계산은 어려우며, 내부 곡률에 대한 판단만이 유 효하다.

\section{3. 곡면 모델링}

\section{1 포인트 샘플링}

일부 포인트를 측정한 경우 모든 포인트들이 중요하고 계측

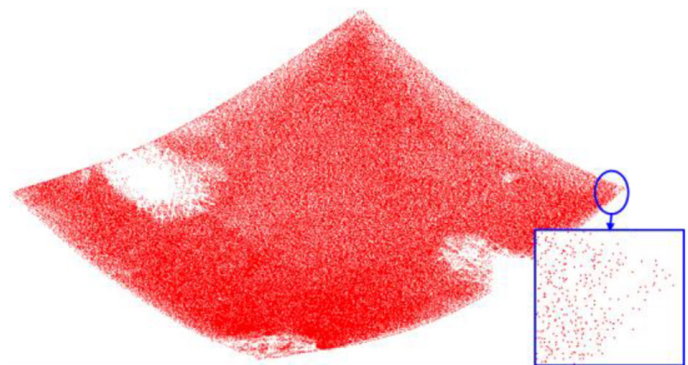

(b) Measured points using 3D laser scanner (21,918 points)

곡면 모델링 작업에 활용된다. 그러나 LVS 및 스캐너를 이용해 서 계측한 경우, 레이저를 이용하는 방식이어서 간격 조절에 따 라 수천 개에서 수백만 개까지 포인트가 획득될 수 있다. 또한 곡부재 주변에 해당하는 부분도 측정될 수 있다. 따라서 우선 곡부재의 영역만을 남기고 주변을 제거해 주는 것이 필요하다. 이는 포인트가 군집해 있는 구간을 나누고 가장 포인트가 많이 몰려있는 영역을 찾으면 곡부재에 해당하는 포인트들의 집합을 만들 수 있다(Park et al., 2016). 또한 곡부재 영역 내에서도 레이 저 난반사 등으로 인해 오차가 발생할 수 있는데, 주변 점들과 비교해서 높이 차이가 많이 발생하는 점들을 제거시켜 준다. 많 은 수의 포인트를 이용해서 곡면을 보간(Interpolation)하는 데에 는 시간이 소요되므로 샘플링(Sampling)을 해서 이용할 필요가 있다. Fig. 7과 같이 계측 영역에 일정한 구를 배치시키고, 구 안 에 1 개의 포인트 만을 남김으로써 균일하게 샘플링을 할 수가 있 다. 구의 배치에 따라 샘플링 결과가 달라 질 수 있는데, 본 연구 에서는 측정된 데이터 전체를 포함하는 공간 박스를 구성하고, 중립면에 우선적으로 구를 배치하고 상하 영역에 대해서 배치하 였다. 구의 크기 또한 곡면 모델링 시간 및 복원 오차에 영향을

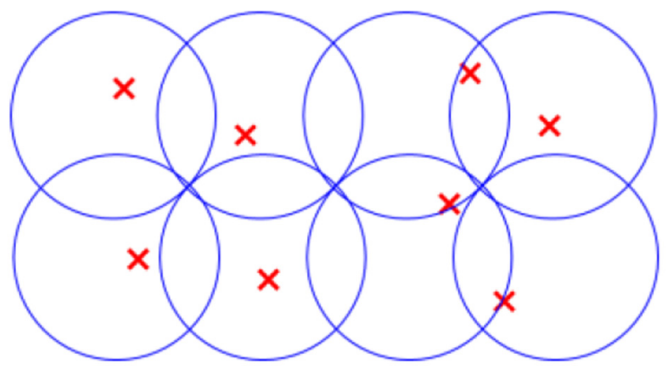

Fig. 7 Sampling points

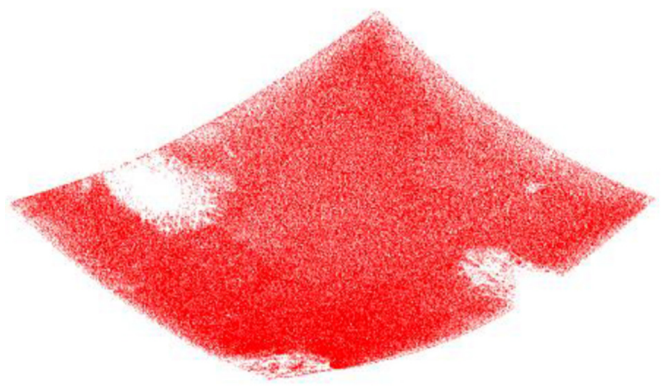

(a) 21,918 points

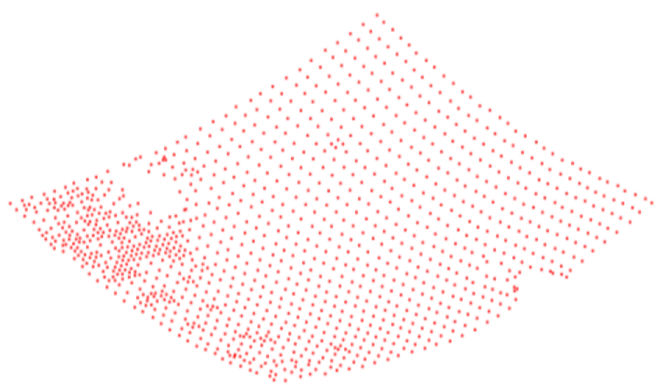

(b) 1,212 points

Fig. 8 Example of sampling 
미친다. 본 연구에서는 $50 \mathrm{~mm}$ 를 사용하였다. Fig. 8은 샘플링 결 과를 보여주고 있으며, 21,918 개의 포인트가 1,212 개로 표현된다.

\section{2 곡면 생성}

일반적으로 측정된 포인트는 계측 편의성을 높이기 위해 일 정한 순서나 방향 없이 무작위로 구성되어 있다. 또한 3.1 절에 서 샘플링 된 포인트 또한 임의로 구성되어 있다. 이를 이용해 서 곡면을 생성하기 위해서는 경계에 해당하는 포인트를 구분 하고, 경계 포인트들을 순서에 맞게 정렬하는 것이 필요하다. 측정된 포인트들을 XY평면으로 이동을 시킨 후, Fig. 9(a)와 같 이 주변 점 들과의 각도를 계산하여 각도 기준표를 작성한다. 그림 Fig. 9(a)는 각도를 16 등분 한 것으로 현재 포인트와 주변 포인트가 이루는 각도 값에 해당하는 부분을 채운다. 빈칸이 연 속적으로 5 개 이상 존재할 경우 이 포인트는 경계에 해당되고, 그렇지 않은 경우는 내부 포인트에 해당된다. 경계에 해당되는 포인트가 넓은 구간에서 측정이 이루어지지 않은 경우는 이와 같은 방법으로 자동으로 분류가 되지 않는다. 이런 경우는 사용 자가 직접 경계와 내부를 구분 지어 주는 것이 필요하다. 내부 와 경계 포인트를 구별한 후에는 경계 포인트들을 순서에 맞게 정렬한다. Fig. 9(b)의 P0에서 P1 방향을 정렬하는 방향이라고 하면, $\mathrm{P} 2$ 는 진행 방향에 가장 가까운 점이여서 다음 순서로 채 택된다. P2에서는 $\mathrm{P} 4$ 가 가장 가까운 점이나, $\mathrm{P} 1, \mathrm{P} 2, \mathrm{P} 3$ 의 각도 가 180 도에 더 가까워 다음 점으로는 $\mathrm{P} 3$ 가 선택된다. 이 경우 거리와 각도의 영향을 모두 고려해서 다음 점을 선택한다. 경계
점들이 순서에 맞게 정렬되면, 포인트들 간의 각도를 고려해서 에지를 나누어 준다. 측정된 모든 점들을 보간을 통해 기저 곡 면(Basis surface)을 생성하고, 경계 곡선을 이용해서 기저 곡면 을 트림한 형태로 최종 계측곡면을 생성한다(Fig. 9(c)). 여기서 기저 곡면은 B-spline을 이용하였다.

\section{4. 가공 완성도 평가}

\section{1 제약 조건을 고려한 곡면 정합}

가공 완성도를 평가하기 위해서는 계측곡면과 설계곡면의 곡 률을 비교해야 하는데, 이를 위해서는 두 곡면을 오차가 최소가 되는 위치에서 정합을 해야 한다. 정합은 두 곡면에서 포인트를 균일하게 샘플링하여 ICP(Iterative closest point)를 이용한다 (Horn, 1987; Besl and Mckay, 1992). 그러나 두 곡면의 초기 위 치에 따라서 전혀 다른 결과가 나올 수 있어서 기준이 되는 위 치를 우선 맞춰 주어야 한다. 가공 부재는 여유 마진이 있는 상 태이며 일반적으로 2 면 또는 3 면 절단을 수행한다. 초기 정합은 두 곡면의 곡선들의 길이 값과 기준면에 해당하는 곡선의 방향 을 이용해서 수행한다(Fig. 10(a)). 식 (1)에서 N은 곡면의 곡선 개수이며, $l_{i}^{M}$ 는 계측곡면의 곡선 길이이고, $l_{j}^{C}$ 는 설계곡면의 곡 선 길이다. 식 (2) $\mathrm{K}$ 는 곡률 오차를 계산하기 위한 샘플링 포인 트 개수이다. 초기 정합은 우선 계측곡면과 설계곡면의 길이가 비슷한 위치를 찾고, 뒤집히지 않도록 $\mathrm{z}$ 방향 오차를 고려해서 식 (2)의 값이 최소가 되는 위치를 찾는다. 길이 만을 고려할 경

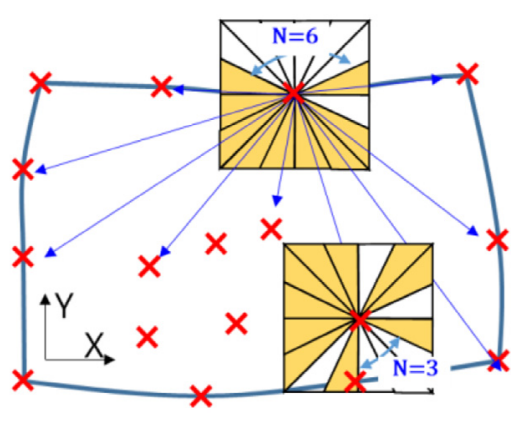

(a) Distinguishing boundary points

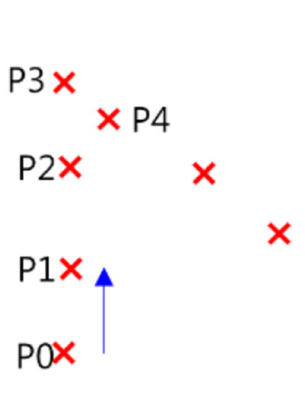

(b) Alignment of boundary points

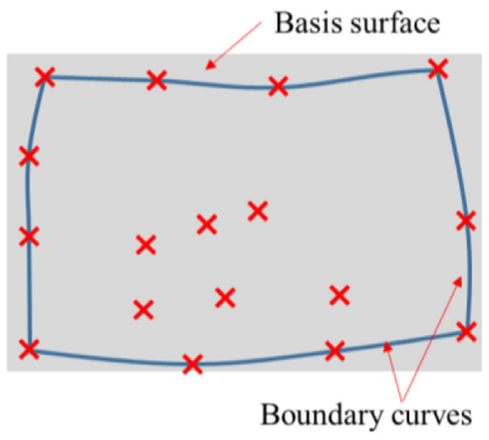

(c) Trimmed surface

Fig. 9 Generation of measured surface

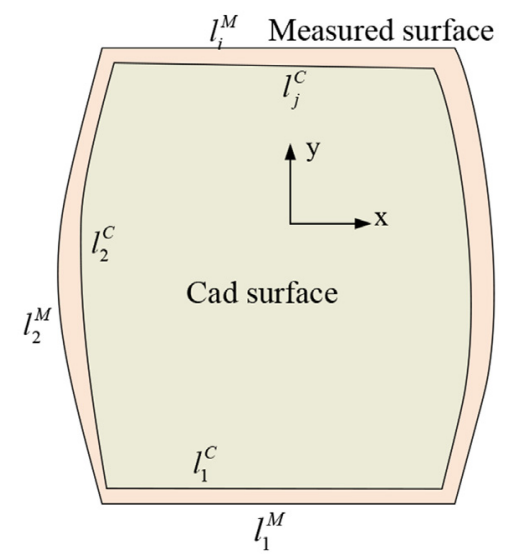

(a) Registration with edge lengths
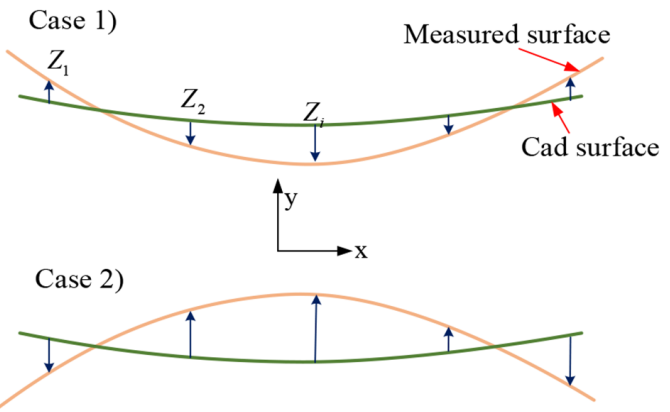

(b) Consideration z-direction errors

Fig. 10 Initial registration measured and CAD surfaces 


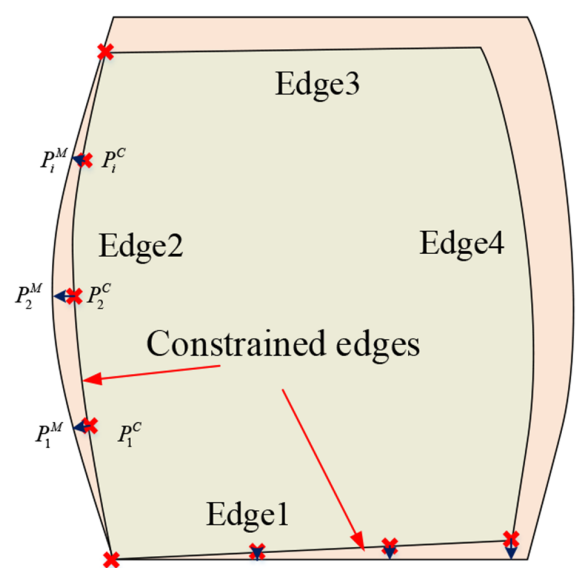

Fig. 11 Registration with constrained edges

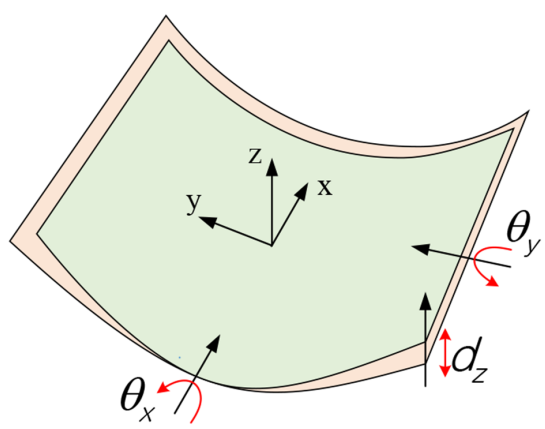

Fig. 12 Registration with constrained edges

우 Fig. 10(b)의 두 번째 경우와 같이 정합이 될 수 있다.

$$
\begin{aligned}
& \phi_{l}=\sum_{i=1, j=1}^{N}\left(l_{i}^{M}-l_{j}^{C}\right)^{2} \\
& \phi_{Z}=\sum_{i=1}^{K}\left(Z_{i}^{M}-Z_{i}^{C}\right)^{2}
\end{aligned}
$$

대략적인 위치를 맞춘 후 기준이 되는 위치를 맞추어야 한다. 만약 기준이 되는 위치가 없는 경우는 두 곡면의 중심점을 기 준으로 하고, 기준이 되는 에지가 있는 경우 매칭되는 에지에 대해서 포인트를 샘플링하여 오차가 최소가 되는 위치를 찾는 다. Fig. 11 은 에지 1,2 가 기준이 되는 2 면 기준 정합 예를 나타 내고 있으며, 두 에지에 대해서 포인트를 샘플링한 후 ICP를 적 용하여 오차가 최소가 되는 위치를 찾는다. 이 때 각 포인트에 서 $\mathrm{z}$ 값은 무시하고 $\mathrm{x}, \mathrm{y}$ 값에 대해서만 수행한다. 일반적으로 $\mathrm{ICP}$ 는 스케일의 변화가 없다고 가정하면 $\mathrm{x}, \mathrm{y}, \mathrm{z}$ 방향 이동 및 회전에 해당하는 6 개의 미지수가 존재한다. 두 집합 간의 포인 트 변환은 식 (3)으로 표현된다.

$$
p^{s^{\prime}}=s R p^{s}+T
$$

여기서, $p^{s^{\prime}}$ 은 이동 후의 포인트를 의미하고, $p^{s}$ 는 이동 전의 포 인트, 즉 설계곡면의 포인트와 매핑 될 계측곡면의 포인트를 의 미한다. 또한, 변수 $s$ 는 스케일링(Scaling) 값으로써 측정에 사용 하는 계측기는 스케일에 의한 차이는 없으므로 값을 1 로 부여 한다. $R$ 은 회전 행렬로써 $\mathrm{x}, \mathrm{y}, \mathrm{z}$ 방향의 회전을 의미하고, $T$ 는
이동 행렬로써 $\mathrm{x}, \mathrm{y}, \mathrm{z}$ 방향의 이동 변위를 의미한다. 이 경우는 $\mathrm{z}$ 값을 무시하므로 $\mathrm{x}, \mathrm{y}$ 방향 이동 및 $\mathrm{z}$ 방향 회전 값만 존재한다.

초기 정합이 완료되면, 기준면을 유지한 상태에서 두 곡면 간의 곡률 오차가 최소가 되는 위치를 찾아야 한다. 이를 위해 설계곡면을 기준으로 샘플링 포인트를 추출하여 이에 대응되 는 계측곡면의 포인트를 찾는다. 추출된 포인트를 이용하여 $\mathrm{ICP}$ 를 적용하며, 이 경우 Fig. 12 와 같이 $\mathrm{x}, \mathrm{y}$ 방향 회전 및 $\mathrm{z}$ 방 향 이동만 존재하도록 해야 한다. 따라서 계산된 결과에서 $\mathrm{x}, \mathrm{y}$ 방향 이동 및 $\mathrm{z}$ 방향 회전 값은 제거시킨 후, 설계곡면을 이동 시킨다.

\section{2 가공 완성도 평가}

가공된 곡면의 완성도를 평가하기 위해 정합 된 상태에서 $\mathrm{z}$ 값 의 차이를 가시화 한다. 이를 위해 곡면에 균일한 삼각형 요소 를 생성하고(Fig. 13), 각 절점에서 설계 곡면에서 계측 곡면까 지의 거리를 계산한다. 각 절점에서 거리 값을 계산하고, Fig. 14 와 같이 삼각형 요소를 세분화해서 색깔을 부여한다.

일반적으로 곡부재의 $\mathrm{z}$ 방향 허용 오차는 $\pm 5 \mathrm{~mm}$ 수준이다. 완 성도를 수치적으로 판단할 때 다음 두 가지 방법으로 접근할 수 있다.

(1) 허용 오차를 벗어나는 비율

(2) 허용 오차를 벗어나는 확률 계산

Fig. 15 에서 각 절점에 대해 $\mathrm{z}$ 방향 오차가 저장되어 있으며, $\mathrm{z}$ 방향 오차가 허용 오차를 벗어난 개수를 계산하면 비율을 계산 할 수 있다. Fig. 15(a)에서 $\pm 5 \mathrm{~mm}$ 를 벗어나는 위치는 세 곳이며 완성도는 6/9(66.7\%)이다. 이는 단순히 개수로만 계산을 하여 경 우에 따라서는 정확한 평가가 되지 못한다. Fig. 15에서 (b), (c) 의 경우 모두 허용 범위 안에 포함되어 개수 기준으로 완성도 는 $100 \%$ 이다. 그러나 이는 후공정에서 오차를 유발할 수 있는 확률은 Fig. 15 (b)가 훨씬 높다. 만약 가공된 인접한 곡판이 정 반 대의 오차를 가진다면, 최대 $10 \mathrm{~mm}$ 까지 오차가 발생할 수 있다. 특히 블록 제작은 대부분 수작업에 의해 이루어져 많은 오차를 유발하는 인자들이 있다. 예를 들어 곡부재 조립을 위해서는 핀지그(Pin zig)를 셋팅하여, 핀지그 위에서 조립 작업을 수행한 다. 이 과정에서 설치 오차가 발생하며, 곡부재 내부에 취부 되 는 내부재 또한 오차를 가지고 있다. 따라서 치수품질로 인해 발생하는 수정 비용을 최대한 줄이기 위해서는 정규 치수에 가 깝게 제작하는 것이 유리하며, 확률 개념을 도입하여 평가함으
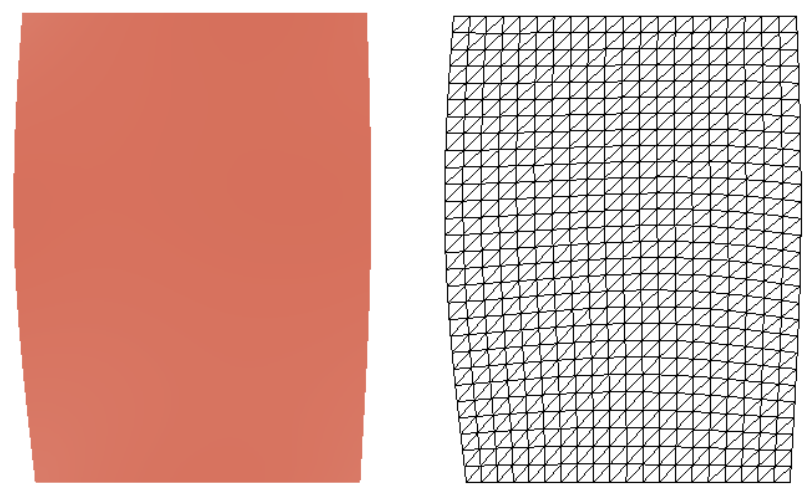

Fig. 13 Triangular mesh generation for curvature comparing 


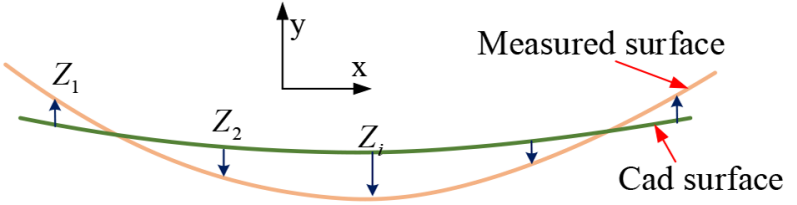

(a) Calculation z- direction errors

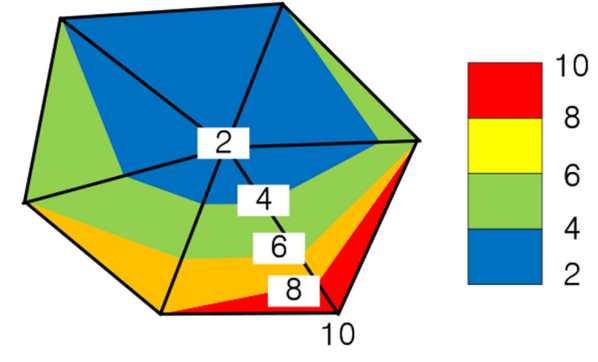

(b) Contouring

Fig. 14 Generation of a z-map using errors

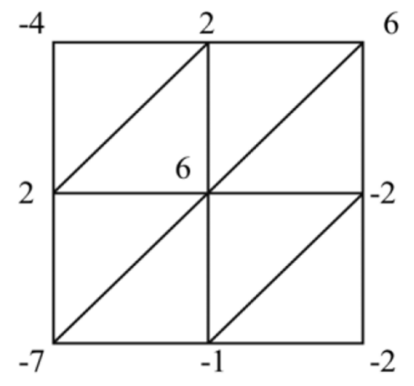

(a) Case 1

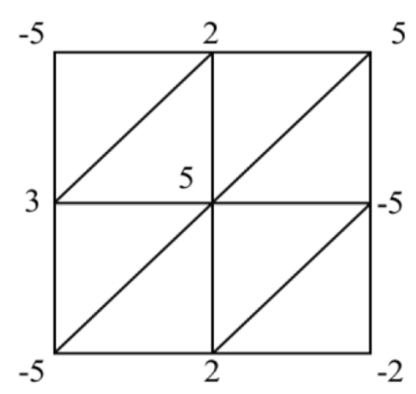

(b) Case 2

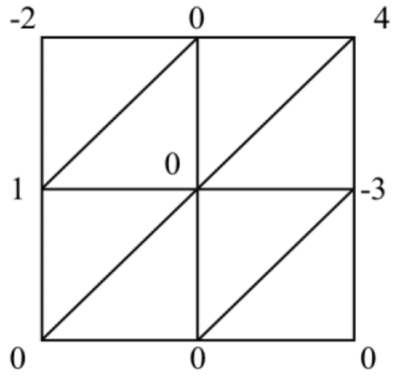

(c) Case3

Fig. 15 Assessment of completion example

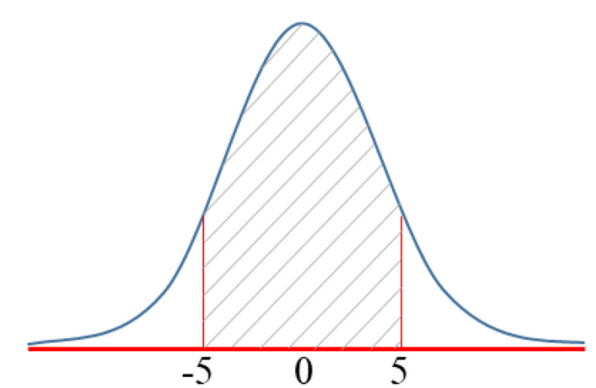

(a) Case 2: Average:0.0, Deviation: 4.27, Assessment: 75.8\%

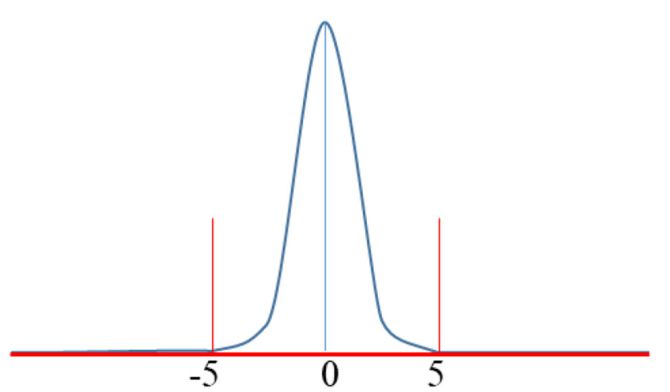

(b) Case 3: Average:0.0, Deviation: 1.93, Assessment: 99\%

Fig. 16 Assessment of completion using probability

Table 1 Assessment of completion

\begin{tabular}{lccc}
\hline \hline & Case 1 & Case 2 & Case 3 \\
\hline Error count & 3 & 0 & 0 \\
Deviation & 4.39 & 4.27 & 1.94 \\
Assessment (Count) & $66.7 \%$ & $100 \%$ & $100 \%$ \\
Assessment (Probability) & $74.6 \%$ & $75.8 \%$ & $99.0 \%$ \\
Assessment (Mixed) & $70.6 \%$ & $87.9 \%$ & $99.5 \%$ \\
\hline
\end{tabular}

로써 이를 보완할 수 있다. 완성도는 평균과 편차를 이용해서허 용 공차를 만족하는 확률로 표현할 수 있다. Fig. 15(b), Fig. $15(\mathrm{c})$ 는 확률로서 판단하면 $75.8 \%, 99 \%$ 로 계산되어 많은 차이가 발생한다(Fig. 16). 그러나 이와 같이 확률로만 판단할 경우 오 차가 허용 공차 $\pm 5 \mathrm{~mm}$ 를 모두 만족시켰음에도 불구하고 Fig. 15(b)의 완성도가 Fig. 15(a)와 비슷한 수준으로 평가가 되었다. 허용 공차를 만족시킬 경우 후 공정에서 문제를 일으킬 가능성 이 상대적으로 줄어들 수 있으므로, 이 두 완성도를 혼합하여 사용하는 평가 방법을 제안한다. 본 연구에서 혼합 방법은 개수
와 확률에 동일 가중치를 적용하여 평균을 구하였다. 이와 같이 혼합하여 적용한 경우 최종 완성도는 $70.6 \%, 87.9 \%$ 및 $99.5 \%$ 이다(Table 1).

\section{3 절단선 마킹}

최종적으로 설계곡면과 같은 크기를 맞추기 위해 여유 마진 부분을 절단한다. 정합된 결과에서 설계곡면의 경계 곡선들을 계측곡면에 투영한 곡선들이 절단선에 해당된다. 가공된 부재 를 절단을 하기 위해서는 이 위치를 부재에 마킹해야 한다. 


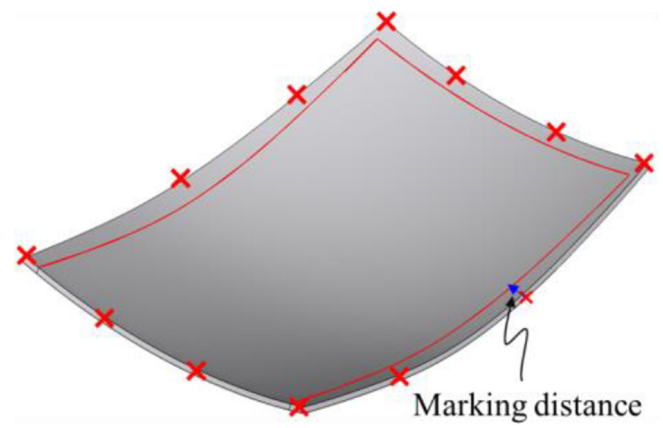

Fig. 17 Cutting lines

Park 등(Park et al., 2016)이 개발한 장비는 갠트리 기준으로 계 측이 이루어져 장비를 이용해서 자동으로 마킹이 가능하지만, 이와 같은 장비를 구성할 수 없을 경우 부재에서 계측된 위치를 기준으로 해서 마킹이 가능하다. 예를 들어 사진계측기를 이용할 경우 타겟이 부착된 위치에서 절단 곡선까지의 거리 값을 계산 해 줌으로써 이를 이용해서 부재에 마킹할 수 있다(Fig. 17). 즉 각 계측 점마다 마킹 선까지의 거리 값을 제공해 주면, 작업자 는 각 계측 포인트에서 이 위치를 부재에 표시하고 이 점들을 연결하여 절단 작업을 수행할 수 있다.

\section{5. 적용 예}

Fig. 18은 계측곡면과 설계곡면에 대해서 구속 조건이 부여되 지 않은 최적 정합 상태를 보여주고 있다. Fig. 18(b)는 설계곡 면을 계측곡면 위로 투영한 후 삼각형 요소망을 생성한 모습이 며, 요소의 각 절점에서 두 곡면 사이의 거리를 계산하여, Fig. 18 (c)와 같이 오차 분포를 가시화 한다. Fig. 19(a)는 아랫면을 구속한 상태에서 정합한 결과이며, Fig. 19(b)는 아랫면과 왼쪽 면 두 에지에 대해서 구속 조건을 고려해서 정합 한 결과이다. 각각에 대한 가공 완성도는 Table 2에 나타나 있으며, 최종 가 공 완성도는 최적일 때가 $85.3 \%, 1$ 개 에지 구속 조건일 때 $81.9 \%, 2$ 개 에지 구속 조건일 때 $80.5 \%$ 이다. 결과에서 알 수 있 듯이 구속 조건이 있는 경우 이를 고려해서 정합을 수행하기 때문에 완성도가 떨어짐을 알 수 있다. Fig. 19(c)는 여유 마진을 절단하기 위한 마킹 위치를 보여주고 있다. 계측된 위치에서 주 어진 값만큼 떨어진 위치가 절단될 위치이다. Fig. 20은 3D 레이 저 스캐너로 측정한 데이터에 대해서 구속 조건이 없는 상태에 서 완성도를 평가한 예이다. 그림에서 알 수 있듯이 경계 부분이 매끄럽지 못하며, 토탈스테이션의 계측 포인트 수가 다소 적고, 두 계측기 간의 오차로 인해 약간의 완성도 값에 차이가 나타났

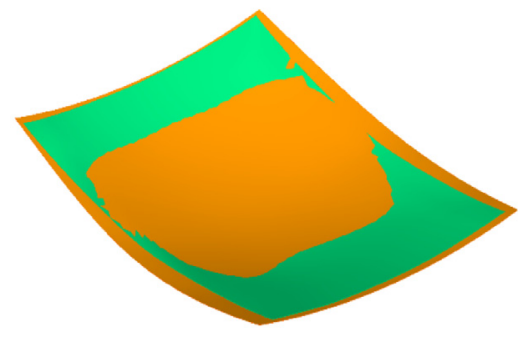

(a) Shading view

Fig. 18 Optimal registration

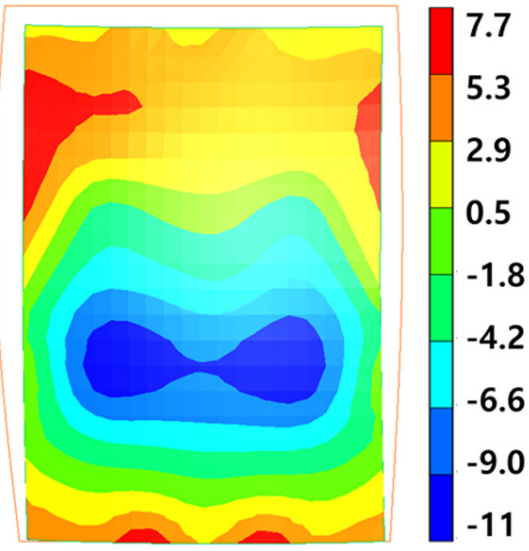

(a) 1 constrained edge

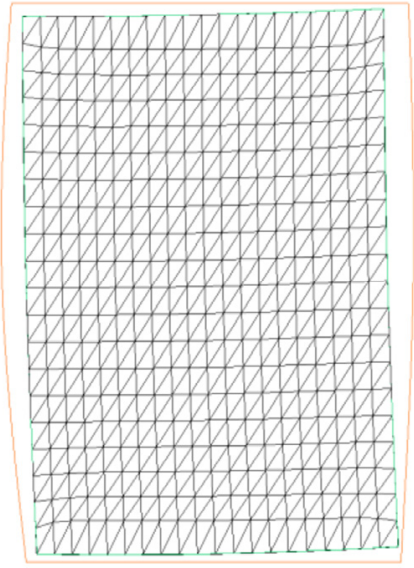

(b) Mesh

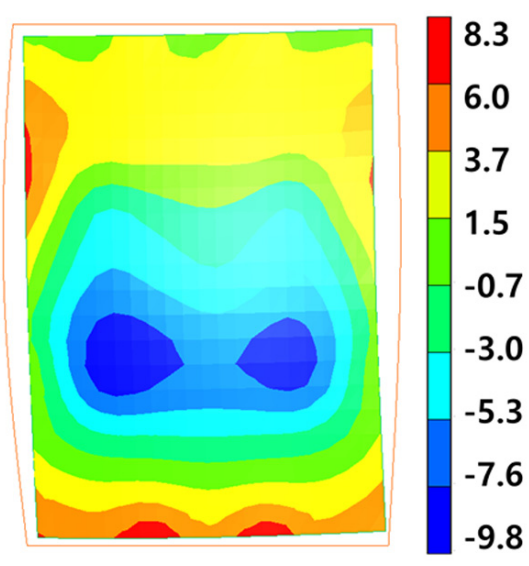

(c) Contouring

7

1.5

0.7

$-3.0$

$-5.3$

$-7.6$

$-9.8$ 
Table 2 Assessment of completion

\begin{tabular}{lccc}
\hline \hline & Center & 1 edge & 2 edges \\
\hline Assessment (Count) & $93.7 \%$ & $91.6 \%$ & $91.8 \%$ \\
Assessment (Probability) & $77 \%$ & $72.1 \%$ & $69.1 \%$ \\
Assessment (Mixed) & $85.3 \%$ & $81.9 \%$ & $80.5 \%$ \\
\hline
\end{tabular}

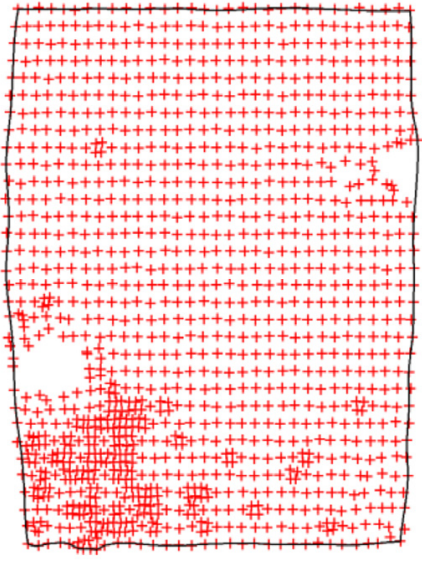

(a) Measured surface using filtered points

Fig. 20 Example of 3D laser scanner

다. 일반적으로 실제 부재가 크게 제작되어 경계 부분의 오차가 크더라도 곡률을 평가하는 데에는 문제가 없다고 판단된다.

본 논문에서 제시한 방법은 포인트 측정 및 형상 전체 측정 방식에 대한 데이터에 대해 적용 가능하여 범용으로 사용될 수 있으며, 자동으로 곡면 모델링을 수행하여 작업 효율성을 높일 수 있다. 또한 부재의 특성에 맞게 제약조건을 고려해서 정합을 수행하여 가공 완성도를 평가하고, 실제 부재 절단을 위한 마킹 값을 산출하여 별도의 자동화 장비 없이 부재에 직접 마킹을 할 수 있다.

\section{6. 결 론}

선수미 등의 곡부재는 후 공정 조립 과정에서 오차가 발생했 을 때, 수정의 어려움으로 인해 많은 추가비용을 유발할 수 있 다. 따라서 정확하게 완성도를 평가하여, 가공 단계에서 양품을 생산해야 한다. 일반 선박 블록처럼 특정 포인트를 측정하여 치 수 품질을 평가하는 데에는 제한이 있으며, 3 차원 계측기를 이 용하여 부재 전체를 측정하여 평가되고 있다. 측정된 데이터로 부터 가공 부재에 대한 곡면을 모델링하고, 이를 설계 곡면과 비교하는데 이 과정에서 작업 기준을 반영한 곡면 정합 방법이 요구되며, 작업자가 쉽게 판단할 수 있도록 가공완성도를 보여 주는 것이 필요하다. 또한 열간 가공으로 인한 수축으로 인해 부재의 크기가 변할 수 있어 주로 마진을 두어 가공을 한 후에 절단 작업을 통해 최종 형상을 완성한다. 본 논문에서는 다양한 3 차원 계측기로부터 측정된 데이터에 대해 곡부재 완성도를 평 가할 수 있는 방법을 제안하였다. 이는 모든 종류의 계측기로부 터 측정된 데이터에 대해서 경계 및 내부를 분류하고, 경계 점 을 정렬하여 계측곡면을 자동으로 모델링하고, 설계곡면과 비 교하여 가공완성도를 평가할 수 있도록 하였다. 계측곡면과 설

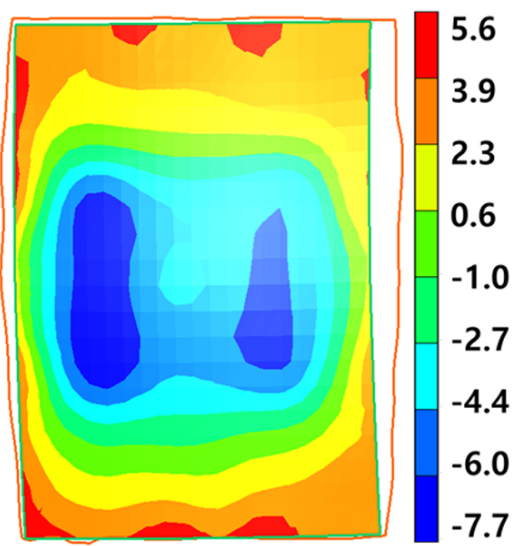

(b) Assessment Count: 97.9\%, Probability: 81.1, Mixed: $89.5 \%$

계곡면은 절단면을 최소화하기 위해 특정 면을 맞출 수 있도록 하였으며, 여유 마진을 실제 절단하는 위치를 기존 계측데이터 를 활용하여 이용할 수 있도록 하였다. 또한 가공완성도는 공정 의 허용오차 안에 들어올 확률적인 개념과 개수를 혼용하여 사 용하였다. 이는 허용오차 안에 물건을 제작하는 것도 중요하고, 최대한 0 오차에 가깝게 제작해야 한다는 관점에서 이와 같이 제안하였다.

측정된 데이터를 이용하여 곡면을 복원하는 과정에서 모델링 오차가 발생할 수 있다. 따라서 부재 크기 및 모양에 따라 어떤 포인트를 이용하는 것이 가장 오차가 적게 발생하는지에 대한 평가가 필요하다. 향후 모델링 오차를 최소화 할 수 있도록 일부 포인트 측정하는 경우 측정 위치에 대한 작업 지시 및 형상 전 체를 스캔하는 경우 샘플링 방법에 대한 추가 연구가 필요하다.

\section{후기}

본 연구는 금오공과대학교 학술 연구비에 의하여 지원된 논 문입니다.

\section{References}

Bae, K.Y., Yang, Y.S., Hyun, C.M., 2012. Analysis of Triangle Heating Technique using High Frequency Induction Heating in Forming Process of Steel Plate. International Journal of Precision Engineering and Manufacturing, 13(4), 539-545.

Besl, P.J., McKay, N.D., 1992. A Method for Registration of 3-D

Shapes. IEEE Transactions on Pattern Analysis and Machine Intelligence, 14(2), 586-606.

Geodetic Systems, 2017. Picture Perfect Measurements. [Online] 
Available at: $<\mathrm{http}: / /$ www.geodetic.com/applications/ship-building/> [Accessed January 2018].

Hiekata, K., Yamato, H., Enomoto, M., Oida, Y., Furukawa, Y., Makino, Y., Sugihiro, T., 2011. Development and Case Studies of Accuracy Evaluation System for Curved Shell Plates by Laser Scanner. Journal of Ship Production and Design, 27(2), 84-90.

Horn, K.P., 1987, Closed-form Solution of Absolute Orientation using Unit Quaternions. Journal of the Optical Society of America, 4(4), 629-633.

Huang, S., Wang, H., Zhao, Y., Lin, Z., 2015. An Analytical Representation of Conformal Mapping for Genus-zero Implicit Surfaces and its Application to Surface Shape Similarity Assessment. Computer-Aided Design, 64, 9-21.

Jung, J.M., Park, C.M., Park, D.C., 2009. A Study on the In-line Assessment of Completion for Fabrication of Curved Plates. Journal of Ocean Engineering and Technology, 23(1), 135-139.

Kwan, S.J., Kim, D.E., 2015. An Efficient Erection Simulation Methodology for the Modular Construction of Offshore Platform Based on Points Cloud Data. ASME 2015 34th International Conference on Ocean, Offshore and Arctic Engineering. American Society of Mechanical Engineers.

Kwon, K.Y., 2016. A Weighted Points Registration Method to Analyze Dimensional Errors Occurring during Shipbuilding Process. Transactions of the Society of CAD/CAM Engineers, 21(2), 151-158.

Li, R., Lee, K.H., Lee, J.M., Nam, B.W., Kim, D.S., 2016. A Study on Matching Method of Hull Blocks Based on Point Clouds for Error Prediction. Journal of the Computational Structural Engineering Institute of Korea, 29(2), 123-130.

Mehrad, V., Xue, D., Gu, P., 2014. Robust Localization to Align Measured Points on the Manufactured Surface with Design Surface for Freeform Surface Inspection. Computer-Aided Design, 53, 90-103.

Park, J., Kim, D., Mun, S., Kwon, K., Lee, J., Ko, K.H., 2016. Automated Thermal Forming of Curved Plates in Shipbuilding: System Development and Validation. International Journal of Computer Integrated Manufacturing, 29(10), 1128-1145.

Park, J., Shin, J., Ko, K.H., 2007. Geometric Assessment for Fabrication of Large Hull Pieces in Shipbuilding. ComputerAided Design, 39(10), 870-881.

Wang, Z., Wu, Z., Zhen, X., Yang, R., Xi, J., 2016. An Onsite Inspection Sensor for the Formation of Hull Plates Based on Active Binocular Stereovision. Proceedings of the Institution of Mechanical Engineers, Part B: Journal of Engineering Manufacture, 230(2), 279-292

Zhou, B., Han, X., Tan, S.K., Liu, Z.C., 2014. Study on Plate Forming Using the Line Heating Process of Multiple-torch. Journal of Ship Production and Design, 30(3), 142-151.

Zhang, X., Yang, Y., Liu, Y., 2011. Feasibility Research on Application of a High Frequency Induction Heat to Line Heating Technology. Journal of Marine Science and Application, 10(4), 456-464. 